IZA DP No. 4917

Automatic Stabilizers, Economic Crisis and Income Distribution in Europe

Mathias Dolls

Clemens Fuest

Andreas Peichl

April 2010 


\title{
Automatic Stabilizers, Economic Crisis and Income Distribution in Europe
}

\author{
Mathias Dolls \\ University of Cologne and IZA \\ Clemens Fuest \\ University of Oxford, \\ University of Cologne, CESifo and IZA \\ Andreas Peichl \\ IZA, University of Cologne, ISER and CESifo
}

Discussion Paper No. 4917
April 2010

IZA

P.O. Box 7240

53072 Bonn

Germany

Phone: +49-228-3894-0

Fax: +49-228-3894-180

E-mail: iza@iza.org

\begin{abstract}
Any opinions expressed here are those of the author(s) and not those of IZA. Research published in this series may include views on policy, but the institute itself takes no institutional policy positions.

The Institute for the Study of Labor (IZA) in Bonn is a local and virtual international research center and a place of communication between science, politics and business. IZA is an independent nonprofit organization supported by Deutsche Post Foundation. The center is associated with the University of Bonn and offers a stimulating research environment through its international network, workshops and conferences, data service, project support, research visits and doctoral program. IZA engages in (i) original and internationally competitive research in all fields of labor economics, (ii) development of policy concepts, and (iii) dissemination of research results and concepts to the interested public.
\end{abstract}

IZA Discussion Papers often represent preliminary work and are circulated to encourage discussion. Citation of such a paper should account for its provisional character. A revised version may be available directly from the author. 
IZA Discussion Paper No. 4917

April 2010

\section{ABSTRACT}

\section{Automatic Stabilizers, Economic Crisis and Income Distribution in Europe*}

This paper investigates to what extent the tax and transfer systems in Europe protect households at different income levels against losses in current income caused by economic downturns like the present financial crisis. We use a multi country micro simulation model to analyse how shocks on market income and employment are mitigated by taxes and transfers. We find that the aggregate redistributive effect of the tax and transfer systems increases in response to the shocks. But the extent to which households are protected differs across income levels and countries. In particular, there is little stabilization of disposable income for low income groups in Eastern and Southern European countries.

JEL Classification: E32, E63, H2, H31

Keywords: automatic stabilization, crisis, inequality, redistribution

Corresponding author:

Andreas Peichl

IZA

P.O. Box 7240

53072 Bonn

Germany

E-Mail: peichl@iza.org

\footnotetext{
* This paper uses EUROMOD version D21. EUROMOD is continually being improved and updated and the results presented here represent the best available at the time of writing. EUROMOD relies on micro-data from 17 different sources for 19 countries. These are the ECHP and EU-SILC by Eurostat, the Austrian version of the ECHP by Statistik Austria; the PSBH by the University of Liège and the University of Antwerp; the Estonian HBS by Statistics Estonia; the Income Distribution Survey by Statistics Finland; the EBF by INSEE; the GSOEP by DIW Berlin; the Greek HBS by the National Statistical Service of Greece; the Living in Ireland Survey by the Economic and Social Research Institute; the SHIW by the Bank of Italy; the PSELL-2 by CEPS/INSTEAD; the SEP by Statistics Netherlands; the Polish HBS by Warsaw University; the Slovenian HBS and Personal Income Tax database by the Statistical Office of Slovenia; the Income Distribution Survey by Statistics Sweden; and the FES by the UK Office for National Statistics (ONS) through the Data Archive. Material from the FES is Crown Copyright and is used by permission. Neither the ONS nor the Data Archive bears any responsibility for the analysis or interpretation of the data reported here. An equivalent disclaimer applies for all other data sources and their respective providers.

This paper is partly based on work carried out during Andreas Peichl's visit to the European Centre for Analysis in the Social Sciences (ECASS) at the Institute for Social and Economic Research (ISER), University of Essex, supported by the Access to Research Infrastructures action under the EU Improving Human Potential Programme. Andreas Peichl is grateful for financial support by Deutsche Forschungsgemeinschaft DFG (PE1675). We would like to thank Cathal O'Donoghue, participants of the 2010 IZA/OECD conference as well as seminar participants in Bonn, Cologne, and at the World Bank for helpful comments and suggestions. We are indebted to all past and current members of the EUROMOD consortium for the construction and development of EUROMOD. The usual disclaimer applies.
} 


\section{Introduction}

Throughout Europe, the current economic and financial crisis has had a severe impact on incomes and employment. While the magnitude of the shocks is usually measured at the macro level, the resulting welfare effects depend not only on the total size of losses but also on their distribution across different groups of society and the cushioning effect of the tax benefit system. This paper investigates to what extent the tax and transfer system protects households at different income levels and in different European countries against income losses and unemployment. ${ }^{1}$ As micro data for an ex-post distributional analysis of the current crisis will become available with a considerable time lag, it is interesting to explore the effects of stylized shocks on the income distribution ex-ante in order to assess the likely distribution of changes in market income and how they translate to changes in disposable income. While this is not a forecasting exercise, our approach does help to understand potential distributional implications of the current economic crisis.

What can we learn from past recessions? Heathcote et al. (forthcoming) refer to the period from 1967-2006 and show for the US that low income households suffer the largest earnings declines in recessions. Households from top percentiles are much less affected which in turn leads to an increase in earnings equality. However, inequality in disposable income rises less than earnings inequality since government transfers, which constitute a large part of disposable income for households at the bottom of the earnings distribution, partly offset income losses. The cushioning role of the government in mitigating increases in earnings inequality can be substantial as is shown by Domeij and Floden (forthcoming) for Sweden, a country with a larger government compared to the US. In Sweden's severe 1992 recession, earnings inequality increased dramatically whereas inequality in disposable income almost remained at its before-crisis level.

Given the experience from past recessions, the question is whether the current economic crisis will have similar distributional consequences. Heathcote et al. (forthcoming), who use the latest US data, show that inequality in disposable income slightly went up in 2008. However, data for 2009 are not available yet, so it is too early for an overall ex-post evaluation of the current crisis. Other simulation

\footnotetext{
${ }^{1}$ Previous research has shown that European tax and transfer systems substantially vary in the degree of automatic income stabilization (Dolls et al. (2009)). But this literature focuses on aggregate automatic stabilization whereas we are interested in income stabilization at different income levels.
} 
studies provide a range of scenarios to assess likely distributional effects. Bargain et al. (2010) use matched employer-employee data to estimate labor demand in Germany and predict employment effects in response to output shocks. They find that low-skilled and part-time/irregular workers face higher risks of employment cuts. In some sectors, but not on average, the same is true for younger and older workers. Callan et al. (2010) analyze the distributional impact of recent public sector pay cuts in Ireland and conclude that they have an immediate inequality reducing effect, though further conclusions depend on the specific implementation.

It is the purpose of this paper to analyze the effects of macro shocks on the income distribution and the role of the tax benefit system to cushion these impacts. We focus on 19 European countries for which a European multi-country microsimulation model is available (EUROMOD). We run two controlled experiments of macro shocks to income and employment in a common microeconometric framework. The first shock is a proportional decline in household gross income by five per cent (income shock). This is the usual way of modeling shocks in simulation studies analyzing automatic stabilizers (Auerbach and Feenberg (2000), Mabbett and Schelkle (2007), Dolls et al. (2009)). But economic downturns typically affect households asymmetrically, with some households losing their jobs and suffering a sharp decline in income and other households being much less affected, as wages are usually rigid in the short term. We therefore consider a second macro shock where the unemployment rate increases such that total household income decreases by $5 \%$ (unemployment shock).

For both scenarios, we compute measures of inequality, poverty and richness to assess the distributional impact of the macro shocks. This analysis enables us to explore diverse effects of the shock scenarios. Further on, we identify how much weight existing pre-crisis tax benefit systems put on different income groups to protect them from income losses. In the next step, we compare the effects across countries in order to evaluate the cushioning effect of different welfare state regimes and to cluster the countries according to their stabilizing effect on the income distribution.

We find that the proportional income shock leads to a reduction in inequality whereas distributional implications of the asymmetric unemployment shock crucially depend on which income groups are affected by rising unemployment. Both shocks increase the headcount ratio for poverty and decrease the counterpart for richness. Turning next to subgroup decompositions, we conclude that European tax benefit systems place unequal weights on the extent how different income groups are pro- 
tected. In case of the unemployment shock, some Eastern and Southern European countries provide little income stabilization for low income groups whereas the opposite is true for the majority of Nordic and continental European countries. With respect to the relationship between income stabilization and redistribution, we find that tax benefit systems with high build-in automatic stabilizers are also those which are more effective in mitigating existing inequalities in market income.

The paper is structured as follows. Section 2 describes the microsimulation model EUROMOD and the different shock scenarios we consider. In Section 3, we provide an institutional overview of tax and transfer systems in Europe and briefly show empirical evidence on pre- and post-tax inequality in European countries as was the case before the start of the current economic crisis. Section 4 presents the results of the distributional analysis and Section 5 concludes.

\section{Data and methodology}

\subsection{Microsimulation using EUROMOD}

We use microsimulation techniques to simulate taxes, benefits and disposable income under different scenarios for a representative micro-data sample of households. Simulation analysis allows conducting a controlled experiment by changing the parameters of interest while holding everything else constant (cf. Bourguignon and Spadaro (2006)). We therefore do not have to deal with endogeneity problems when identifying the effects of the policy reform under consideration.

Simulations are carried out using EUROMOD, a static tax-benefit model for 19 EU countries ${ }^{2}$, which was designed for comparative analysis. ${ }^{3}$ EUROMOD is characterised by greater flexibility than typical national models, to accommodate a range of different tax-benefit systems. For instance, the model can easily handle different units of assessment, income definitions for tax bases and benefit means-

\footnotetext{
${ }^{2}$ These are Austria (AT), Belgium (BE), Denmark (DK), Estonia (EE), Finland (FI), France (FR), Germany (GE), Greece (GR), Hungary (HU), Ireland (IR), Italy (IT), Luxembourg (LU), the Netherlands (NL), Poland (PL), Portugal (PT), Slovenia (SI), Spain (SP), Sweden (SW) and the United Kingdom (UK).

${ }^{3}$ For further information on EUROMOD see Sutherland $(2001,2007)$. There are also country reports available with detailed information on the input data, the modeling and validation of each tax benefit system, see http://www.iser.essex.ac.uk/research/euromod. The tax-benefit systems included in the model have been validated against aggregated administrative statistics as well as national tax-benefit models (where available), and the robustness checked through numerous applications (see, e.g., Bargain (2006)).
} 
tests, the order and structure of instruments. Overall, a common framework allows the comparison of countries in a consistent way.

EUROMOD can simulate most direct taxes and benefits except those based on previous contributions as this information is usually not available from the crosssectional survey data used as input datasets. Information on these instruments is taken directly from the original data sources. The model assumes full benefit takeup and tax compliance, focusing on the intended effects of tax-benefit systems. The main stages of the simulations are the following. First, a micro-data sample and tax-benefit rules are read into the model. Then for each tax and benefit instrument, the model constructs corresponding assessment units, ascertains which are eligible for that instrument and determines the amount of benefit or tax liability for each member of the unit. Finally, after all taxes and benefits in question are simulated, disposable income is calculated.

\subsection{Scenarios}

The existing literature on income stabilization through the tax and transfer system has concentrated on increases in earnings or gross incomes to examine the stabilizing impact of tax benefit systems (cf. Auerbach and Feenberg (2000), Mabbett and Schelkle (2007)). In the light of the current economic crisis, there is much more interest in a downturn scenario. Reinhart and Rogoff (2009) stress that recessions which follow a financial crisis have particularly severe effects on asset prices, output and unemployment. Therefore, we are interested not only in a scenario of a uniform decrease in incomes but also in an increase of the unemployment rate. We compare a scenario where gross incomes are proportionally decreased by $5 \%$ for all households (income shock) to a scenario where some households are made unemployed and therefore lose all their labor earnings (unemployment shock). In the latter scenario, the unemployment rate increases such that total household income decreases by $5 \%$ as well in order to make both scenarios as comparable as possible. ${ }^{4}$

The increase of the unemployment rate is modeled through reweighting of our samples. ${ }^{5}$ The weights of the unemployed are increased while those of the employed

\footnotetext{
${ }^{4}$ Our scenarios can be seen as a conservative estimate of the expected impact of the current crisis (see Reinhart and Rogoff (2009) for effects of previous crises). The (qualitative) results are robust with respect to different sizes of the shocks. The results for the unemployment shock do not change much when we model it as an increase of the unemployment rate by 5 percentage points for each country.

${ }^{5}$ For the reweigthing procedure, we follow the approach of Immvervoll et al. (2006), who have
} 
with similar characteristics are decreased, i.e., in effect, a fraction of employed households is made unemployed. With this reweighting approach we control for several individual and household characteristics that determine the risk of becoming unemployed (see Appendix A.2). The implicit assumption behind this approach is that the socio-demographic characteristics of the unemployed remain constant. ${ }^{6}$

\subsection{Automatic Stabilization}

In order to explore the build-in automatic stabilizers of existing pre-crisis tax benefit systems, in a companion paper (Dolls et al. (2009)), we suggest the income stabilization coefficient $\tau^{I}$ which measures the sensitivity of disposable income, $Y_{i}^{D}$, with respect to market income, $Y_{i}^{M}$, as a measure for automatic stabilization. Market income $Y_{i}^{M}$ of individual $i$ is defined as the sum of all incomes from market activities:

$$
Y_{i}^{M}=E_{i}+Q_{i}+I_{i}+P_{i}+O_{i}
$$

where $E_{i}$ are earnings, $Q_{i}$ business income, $I_{i}$ capital income, $P_{i}$ property income, and $O_{i}$ other income. Disposable income $Y_{i}^{D}$ is defined as market income minus net government intervention $G_{i}=T_{i}+S_{i}-B_{i}$ :

$$
Y_{i}^{D}=Y_{i}^{M}-G_{i}=Y_{i}^{M}-\left(T_{i}+S_{i}-B_{i}\right)
$$

where $T_{i}$ are direct taxes, $S_{i}$ employee social insurance contributions, and $B_{i}$ are social cash benefits (i.e. negative taxes). We derive $\tau^{I}$ from a general functional relationship between disposable income and market income:

$$
\tau^{I}=\tau^{I}\left(Y^{M}, T, S, B\right)
$$

The derivation can be either done on the macro or on the micro level. On the macro level, it holds that the aggregate change in market income $\left(\Delta Y^{M}\right)$ is

also simulated an increase in unemployment through reweighting of the sample. Their analysis focuses on changes in absolute and relative poverty rates after changes in the income distribution and the employment rate. A different approach would be to randomly select people who become unemployed, cf. Figari et al. (2010).

${ }^{6}$ Cf. Deville and Särndal (1992) and DiNardo et al. (1996). This approach is equivalent to estimating probabilities of becoming unemployed (see, e.g., Bell and Blanchflower (2009)) and then selecting the individuals with the highest probabilities when controlling for the same characteristics in the reweighting estimation (see Herault (2009)). 
transmitted via $\tau^{I}$ into an aggregate change in disposable income $\left(\Delta Y^{D}\right)$ :

$$
\Delta Y^{D}=(1-\tau) \Delta Y^{M}
$$

However, one problem when computing $\tau^{I}$ with macro data is that this data includes behavioral and general equilibrium effects as well as active policy. Therefore, a measure of automatic stabilization based on macro data captures all these effects. In order to single out the pure size of automatic stabilization, we compute $\tau^{I}$ using arithmetic changes $(\Delta)$ in total disposable income $\left(\sum_{i} \Delta Y_{i}^{D}\right)$ and market income $\left(\sum_{i} \Delta Y_{i}^{M}\right)$ based on micro level information:

$$
\begin{aligned}
\sum_{i} \Delta Y_{i}^{D} & =\left(1-\tau^{I}\right) \sum_{i} \Delta Y_{i}^{M} \\
\tau^{I} & =1-\frac{\sum_{i} \Delta Y_{i}^{D}}{\sum_{i} \Delta Y_{i}^{M}}=\frac{\sum_{i}\left(\Delta Y_{i}^{M}-\Delta Y_{i}^{D}\right)}{\sum_{i} \Delta Y_{i}^{M}}=\frac{\sum_{i} \Delta G_{i}}{\sum_{i} \Delta Y_{i}^{M}}
\end{aligned}
$$

Thus, the coefficient can be decomposed into its components which include taxes, social insurance contributions and benefits:

$$
\tau^{I}=\sum_{f} \tau_{f}^{I}=\tau_{T}^{I}+\tau_{S}^{I}+\tau_{B}^{I}=\frac{\sum_{i} \Delta G_{i}}{\sum_{i} \Delta Y_{i}^{M}}=\frac{\sum_{i}\left(\Delta T_{i}+\Delta S_{i}-\Delta B_{i}\right)}{\sum_{i} \Delta Y_{i}^{M}}
$$

The main results of Dolls et al. (2009) are shown in Figure $1 .^{7}$ In case of the income shock (upper panel), approximately $38 \%$ of the shock would be absorbed by automatic stabilizers in the EU. Within the EU, there is considerable heterogeneity, and results for overall stabilization of disposable income range from a value of $25 \%$ for Estonia to $56 \%$ in Denmark. In general, automatic stabilizers in Eastern and Southern European countries are considerably lower than in Continental and Northern European countries.

In case of the unemployment shock (lower panel), automatic stabilizers absorb $47 \%$ of the shock in the EU, thus exceeding stabilization in case of the income shock by 9 percentage points. The decomposition of overall stabilization into the components income taxes, social insurance contributions and benefits shows that benefits accounting for $40 \%$ of overall stabilization are a main driver of disposable income stabilization. Highest values for $\tau^{I}$ are again found in the Nordic countries

\footnotetext{
${ }^{7}$ In this paper, we also analyze the importance of liquidity constraints for demand stabilization.
} 
Denmark and Sweden whereas automatic stabilizers in Estonia, Italy and Poland are at the lower end.

Figure 1: Decomposition of income stabilization coefficient in both scenarios for different countries

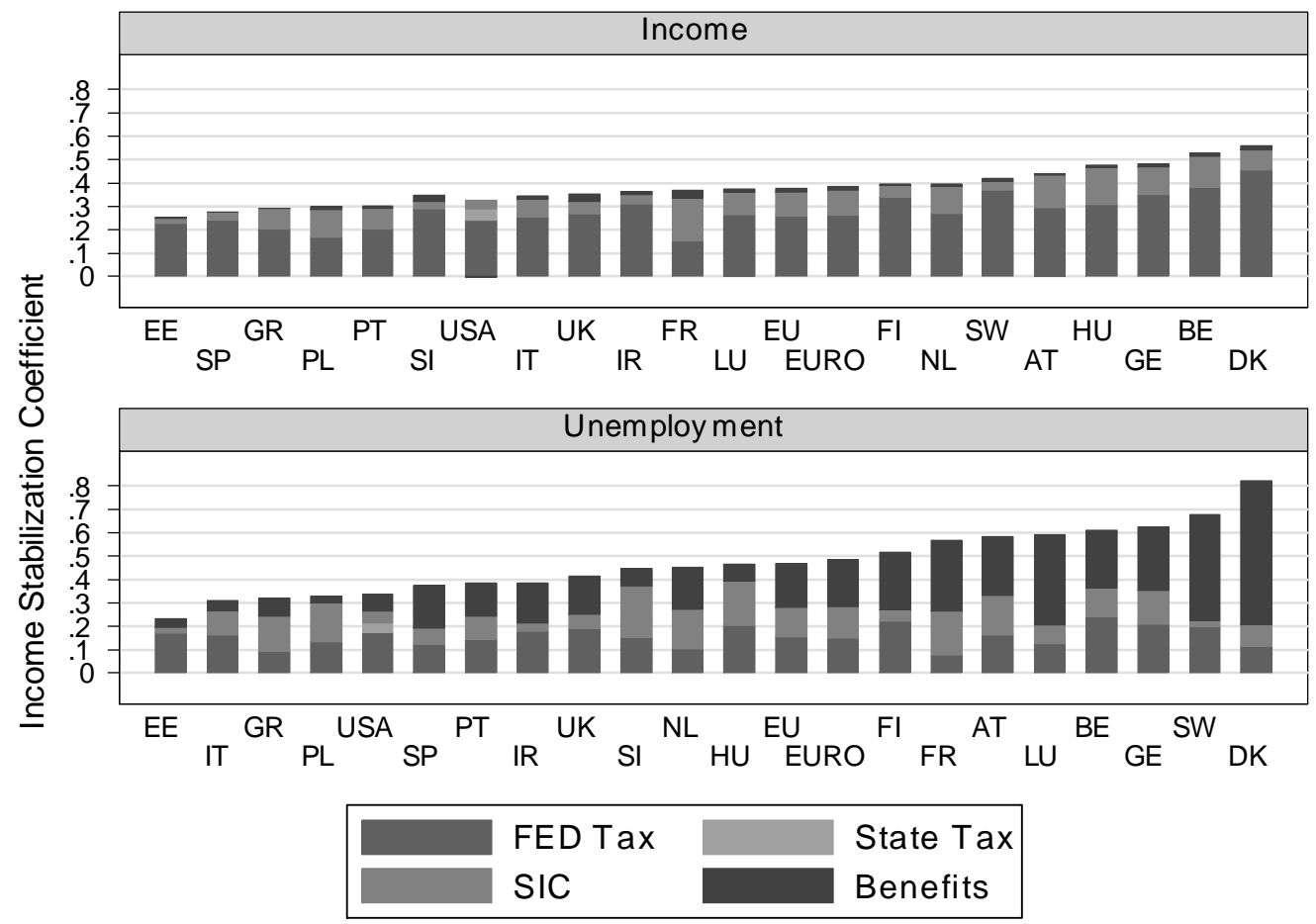

Source: Dolls et al. (2009).

\subsection{Inequality measurement}

Let an income distribution be a random variable $X=\left(x_{1}, x_{2}, \ldots, x_{n}\right)$, where $x_{i} \geq 0$ is the income of individual $i, i=1, \ldots n$. The Gini coefficient of inequality is defined as:

$$
I_{\text {Gini }}=\sum_{i=1}^{n} l_{i} \frac{2 i-n-1}{n-1}
$$

In case of maximum inequality, $I_{\text {Gini }}^{*}$ corresponds to one, and in the case that all values are equal, $I_{\text {Gini }}^{*}$ corresponds to zero. 
We use disposable income defined as market income minus direct taxes and social contributions plus cash benefits (including pensions) for our distributional analyses. The unit of analysis is the individual. To compensate for different household structures and possible economies of scale in households, we use equivalent incomes throughout the analyses. For each person, the equivalent (per-capita) total disposable income is its household's total disposable income divided by the equivalent household size according to the modified OECD scale. ${ }^{8}$

\section{Tax and transfer systems in Europe}

\subsection{Tax benefit systems}

The existing income tax systems in the 19 European countries under consideration offer considerable variety. As Table 1 shows, all Western European countries in our sample have graduated rate schedules with a number of brackets ranging from 2 (Ireland) to 16 (Luxembourg), with the top marginal income tax rate ranging from $38 \%$ (Luxembourg) to $59 \%$ in Denmark. There are also considerable differences across the Eastern European countries. Estonia has a flat tax system, with a single rate of $22 \%$ and a basic allowance of 1.304 Euro, while the other Eastern European countries in our sample apply graduated tax schedules with a comparatively small number of brackets (2-3) and relatively low top marginal rates. Interestingly, Slovenia and Poland have very similar income tax schedules as the Western European countries, with highest rates around $40 \%$, but with a lower amount belonging to the $0 \%$ bracket.

European countries do not only differ in their income tax schedules but also in the design of their system of social protection and redistribution. In each country, direct and indirect taxes as well as social insurance contributions (SIC) are used to finance the welfare state (see Table 2 for an overview). The weight in the tax mix of these components depends on the structural design of the tax benefit system in each country. For the Continental countries it is evident that the SIC are more important to finance the welfare state than the direct taxes. This is also true for Eastern Europe, while in the Nordic countries the SIC play only a minor role. Denmark relies

\footnotetext{
${ }^{8}$ The modified OECD scale assigns a weight of 1.0 to the head of household, 0.5 to every household member aged 14 or more and 0.3 to each child aged less than 14 . Summing up the individual weights gives the household specific equivalence factor.
} 
Table 1: Income tax systems 2007

\begin{tabular}{|c|c|c|c|c|}
\hline & No of brackets & Lowest rate & Highest rate & Form of main tax relief \\
\hline$\overline{\mathrm{AT}}$ & 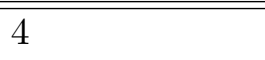 & $38.3 \%$ & $50.0 \%$ & (0\% bracket $(10,000$ EUR $)$ \\
\hline $\mathrm{BE}$ & 5 & $25.0 \%$ & $50.0 \%$ & tax allowance $(6,040 \mathrm{EUR})$ \\
\hline DK & 3 & $\begin{array}{l}\text { state } 5.48 \% \text {. } \\
\text { local } 24.6 \%\end{array}$ & $\begin{array}{l}\text { state } 15 \% \text {. } \\
\text { local } 24.6 \%\end{array}$ & tax allowance \\
\hline $\mathrm{EE}$ & flat tax & $22.0 \%$ & $22.0 \%$ & basic allowance 1,304 EUR \\
\hline FI & 4 & $\begin{array}{l}\text { state } 8.5 \% \\
\text { local } 16 \%\end{array}$ & $\begin{array}{l}\text { state } 31.5 \% \text {. } \\
\text { local } 21 \%\end{array}$ & $\begin{array}{l}0 \% \text { bracket }(12,600 \mathrm{EUR}) . \text { state } \\
\text { tax allowance. local }\end{array}$ \\
\hline FR & 4 & $5.5 \%$ & $40.0 \%$ & $0 \%$ bracket $(5,614$ EUR $)$ \\
\hline GE & formula & $15.8 \%$ & $44.3 \%$ & $0 \%$ bracket $(7,664$ EUR $)$ \\
\hline GR & 3 & $15.0 \%$ & $40.0 \%$ & $0 \%$ bracket $(12,000$ EUR $)$ \\
\hline $\mathrm{HU}$ & 2 & $18.0 \%$ & $36.0 \%$ & tax credit \\
\hline IR & 2 & $20.0 \%$ & $41.0 \%$ & tax allowance \\
\hline IT & 5 & $23.0 \%$ & $43.0 \%$ & tax credit \\
\hline $\mathrm{LU}$ & 16 & $8.0 \%$ & $38.0 \%$ & $0 \%$ bracket $(10,335$ EUR $)$ \\
\hline NL & 4 & $33.6 \%$ & $52.0 \%$ & tax credit \\
\hline PL & 3 & $19.0 \%$ & $40.0 \%$ & 0\% bracket $(3,091$ EUR $)$ \\
\hline $\mathrm{PT}$ & 6 & $10.5 \%$ & $40.0 \%$ & tax credit \\
\hline SI & 3 & $16.0 \%$ & $41.0 \%$ & tax allowance $(2,800 \mathrm{EUR})$ \\
\hline $\mathrm{SP}$ & 4 & $24.0 \%$ & $43.0 \%$ & tax allowance $(5,151 \mathrm{EUR})$ \\
\hline SW & 2 & $\begin{array}{l}\text { state } 20 \% . \\
\text { local } 31.6 \%\end{array}$ & $\begin{array}{l}\text { state } 25 \% . \\
\text { local } 31.6 \%\end{array}$ & tax allowance \\
\hline UK & 3 & $10.0 \%$ & $40.0 \%$ & tax allowance $(5,225$ EUR $)$ \\
\hline
\end{tabular}

almost exclusively on taxes for financing the welfare state. In Southern European countries, indirect taxes tend to play the most important role. This is even more true for Eastern Europe. With few exceptions, there is a north-to-south and west-to-east decline with respect to the ratio of direct taxes and social insurance contributions to indirect taxes. The level of social protection (in terms of expenditures as $\%$ of GDP) is high in Nordic and Continental countries (an exception is Luxembourg) and particularly low in Eastern Europe as well as Ireland. A perhaps trivial but still interesting observation from Table 2 is that the level of social expenditures is correlated with the level of taxes and contributions.

\subsection{Distribution and Redistribution}

How do European countries differ in terms of pre-tax and post-tax inequality? The 
Table 2: Tax benefit mix (as \% of GDP) in 2005

\begin{tabular}{r|c|c|c|c|c|c} 
& $\begin{array}{c}\text { Total } \\
\text { Taxes }\end{array}$ & $\begin{array}{c}\text { Indirect } \\
\text { Taxes }\end{array}$ & $\begin{array}{c}\text { Direct } \\
\text { Taxes }\end{array}$ & $\begin{array}{c}\text { Social } \\
\text { Contr. }\end{array}$ & $\begin{array}{c}\text { Dir. Taxes+SIC } \\
\text { /nd. Taxes }\end{array}$ & $\begin{array}{c}\text { Social } \\
\text { Expen. }\end{array}$ \\
\hline \hline AT & 42.0 & 14.7 & 12.9 & 14.5 & 1.9 & 28.8 \\
BE & 45.5 & 13.9 & 17.8 & 13.9 & 2.3 & 29.7 \\
DK & 50.3 & 17.9 & 31.4 & 1.1 & 1.8 & 30.1 \\
EE & 30.9 & 13.5 & 7.1 & 10.4 & 1.3 & 12.5 \\
FI & 43.9 & 14.1 & 17.9 & 12.0 & 2.1 & 26.7 \\
FR & 44.0 & 15.8 & 11.9 & 16.4 & 1.8 & 31.5 \\
GE & 38.8 & 12.1 & 10.3 & 16.3 & 2.2 & 29.4 \\
GR & 34.4 & 12.9 & 9.5 & 12.1 & 1.7 & 24.2 \\
HU & 38.5 & 15.8 & 9.1 & 13.6 & 1.4 & 21.9 \\
IR & 30.8 & 13.6 & 12.4 & 4.8 & 1.3 & 18.2 \\
IT & 40.6 & 14.5 & 13.5 & 12.6 & 1.8 & 26.4 \\
LU & 38.2 & 13.4 & 14.1 & 10.7 & 1.9 & 21.9 \\
NL & 38.2 & 13.1 & 11.9 & 13.1 & 1.9 & 28.2 \\
PL & 34.2 & 13.9 & 7.0 & 13.7 & 1.5 & 19.6 \\
PT & 35.3 & 15.3 & $8.6 *$ & 11.3 & 1.3 & $24.7 *$ \\
SI & 40.5 & 16.4 & 9.3 & 14.8 & 1.5 & 23.4 \\
SP & 35.6 & 12.5 & 11.4 & 12.2 & 1.9 & 20.8 \\
SW & 51.3 & 17.3 & 20.1 & 13.8 & 2.0 & 32.0 \\
UK & 37.0 & 13.3 & 16.8 & 6.9 & 1.8 & 26.8 \\
Source: Eurostat. Notes: * Numbers for Portugal are from 2004
\end{tabular}

first column of Table 3 indicates that inequality in market income, $Y_{i}^{M}$, as measured by the Gini coefficient, displays huge disparities among the European countries of our sample. Coefficients range from 0.39 to 0.55 , with values above 0.5 in some Southern and Eastern European countries (Estonia, Greece, Hungary, Poland, Portugal and Slovenia). At the lower end, the Netherlands is the only country with a Gini coefficient for equivalised market income which is below 0.4. Closest to the Netherlands are Sweden and Austria, both with values below 0.45.

Column 2 shows that post-tax inequality, i.e. the Gini coefficient based on disposable income, is substantially lower than pre-tax inequality in all countries. Thus, existing inequalities in market income are mitigated by European tax benefit systems through a substantial degree of redistribution. Although there are significant differences in the size of redistribution, the overall inequality ranking of the countries basically remains the same.

Finally, the last two columns of Table 3 show the absolute and relative differences between the pre- and post-tax Gini coefficients as measures of redistribution (see 
Table 3: Distribution and redistribution in the baseline

\begin{tabular}{lllrr}
\hline \hline & $G_{B}^{Y^{M}}$ & $G_{B}^{Y D}$ & $\Delta G_{B}^{Y^{D}-Y^{M}}$ & $\Delta \sigma_{B}^{Y^{D}-Y^{M}}$ \\
\hline AT & 0.441 & 0.227 & -0.214 & -48.569 \\
BE & 0.491 & 0.247 & -0.244 & -49.704 \\
DK & 0.457 & 0.232 & -0.226 & -49.344 \\
EE & 0.509 & 0.324 & -0.185 & -36.403 \\
FI & 0.484 & 0.269 & -0.215 & -44.464 \\
FR & 0.487 & 0.260 & -0.226 & -46.523 \\
GE & 0.494 & 0.268 & -0.225 & -45.667 \\
GR & 0.502 & 0.323 & -0.179 & -35.590 \\
HU & 0.547 & 0.274 & -0.273 & -49.885 \\
IR & 0.459 & 0.309 & -0.150 & -32.642 \\
IT & 0.498 & 0.348 & -0.149 & -30.024 \\
LU & 0.472 & 0.243 & -0.229 & -48.459 \\
NL & 0.386 & 0.247 & -0.139 & -35.902 \\
PL & 0.545 & 0.332 & -0.213 & -39.102 \\
PT & 0.507 & 0.361 & -0.146 & -28.784 \\
SI & 0.504 & 0.270 & -0.234 & -46.353 \\
SP & 0.467 & 0.294 & -0.172 & -36.924 \\
SW & 0.437 & 0.234 & -0.203 & -46.523 \\
UK & 0.496 & 0.306 & -0.190 & -38.353 \\
\hline \hline Source: Own calculations based on EUROMOD.
\end{tabular}

also Fuest et al. (2010)). In countries such as Austria, Belgium, Denmark, Hungary or Luxembourg, tax benefit systems reduce inequalities in market income by almost $50 \%$. At the other end of the spectrum, we find lowest redistribution in Portugal and Italy with a reduction in inequality of approximately $30 \%$.

\section{Effects of shocks on income distribution}

\subsection{Overall distribution}

What are the distributional consequences of the two macro shocks described above? Table 4 shows the percentage changes in the Gini coefficient and in the headcount ratios for being poor or rich, all based on equivalent disposable income.

While the proportional income shock (IS) leads to a reduction of the Gini coefficient in all countries, the asymmetric unemployment shock (US) increases inequality in 15 out of 19 countries. In the latter case, we find a reduction of the Gini coefficient only in Denmark, Luxembourg, Portugal and Sweden. In the case of the income 
shock, the largest reductions of the Gini coefficient occur in Belgium, Denmark, Sweden and the UK (all $>2 \%$ ), the smallest ones in Greece and Slovenia (each $<0.5 \%$ ). In the case of the unemployment shock, distributional implications crucially depend on which income groups are hardest hit by unemployment and income losses. If low income groups are the first who loose their jobs during a recession, one can expect an increase in inequality. However, if also middle or upper income groups are affected which seems to be relevant especially in long-lasting recessions such as the current one, distributional implications become more ambiguous. This ambiguity in terms of distributional effects of an asymmetric shock is reflected in the positive and negative signs of the Gini change.

Comparing the headcount ratios for both shock scenarios, we can conclude that, not surprisingly, in case of the unemployment shock richness is decreasing less than in the case of the proportional income shock. ${ }^{9}$ With the exception of Slovenia, the percentage reduction of rich people is substantially higher in the latter shock scenario. However, no such clear conclusion can be drawn considering the percentage change in poverty. In countries such as Ireland or the United Kingdom, the asymmetric unemployment shock leads to a much stronger increase in the headcount for the poor than the income shock. However, the opposite is true for countries such as Greece, Luxembourg or the Netherlands. Here, distributional implications depend again crucially on which income groups are actually the first who become unemployed in a recession.

What is the effect of the two shock scenarios on market income inequality and the amount of redistribution achieved by the tax and transfer system? Table 5 sheds further light on the implications for the overall income distribution. The first column shows the percentage change of the Gini coefficient based on equivalised market income between the unemployment shock scenario and the baseline $\left(\left(G_{U S}^{Y^{M}}-\right.\right.$ $\left.\left.G_{B}^{Y^{M}}\right) / G_{B}^{Y^{M}}\right) .{ }^{10}$ With the exception of Portugal, we find an increase in inequality which is highest in Ireland, Denmark, the UK and Sweden (all $>2 \%$ ) and lowest in Greece, Hungary, Italy, Poland and Slovenia (all $<1 \%$ ).

The last two columns of Table 5 show how the difference between the Gini coefficients based on equivalised disposable and market income has changed comparing

\footnotetext{
${ }^{9}$ The reweighting approach used for modeling an increase in unemployment is implicitly based on the assumption that the socio-demographic characteristics of the unemployed remain constant. A more in-depth description of the approach can be found in the Appendix.

${ }^{10}$ Note that the Gini coefficient of market income does not change in case of the proportional shock.
} 
Table 4: Effect of shocks on income distribution

\begin{tabular}{lrrr|rrr}
\hline \hline & \multicolumn{3}{c|}{ Income shock } & \multicolumn{3}{c}{ Unemployment shock } \\
\hline & Gini & Poor & \multicolumn{1}{c}{ Rich } & \multicolumn{1}{|c}{ Gini } & Poor & Rich \\
\hline AT & -1.297 & 4.760 & -12.088 & 0.304 & 4.421 & -3.619 \\
BE & -2.270 & 2.673 & -16.241 & 0.126 & 3.869 & -4.322 \\
DK & -2.064 & 3.838 & -18.903 & -0.218 & 1.176 & -5.054 \\
EE & -1.622 & 4.529 & -11.508 & 0.914 & 6.542 & -2.989 \\
FI & -1.806 & 5.622 & -13.981 & 0.347 & 7.104 & -3.428 \\
FR & -1.422 & 7.458 & -9.947 & 0.210 & 4.083 & -2.409 \\
GE & -1.489 & 4.141 & -12.982 & 0.445 & 6.245 & -3.469 \\
GR & -0.338 & 7.288 & -11.355 & 0.166 & 2.509 & -2.820 \\
HU & -0.604 & 5.701 & -9.241 & 0.518 & 5.612 & -3.861 \\
IR & -1.335 & 3.701 & -12.591 & 1.154 & 10.295 & -7.285 \\
IT & -0.735 & 4.910 & -5.857 & 0.507 & 3.567 & -2.234 \\
LU & -1.233 & 9.994 & -14.276 & -0.225 & 1.335 & -3.843 \\
NL & -1.232 & 10.629 & -16.256 & 0.652 & 7.892 & -3.985 \\
PL & -0.923 & 6.749 & -9.692 & 0.281 & 3.757 & -2.639 \\
PT & -0.611 & 4.693 & -6.055 & -0.709 & 1.528 & -2.667 \\
SI & -0.318 & 0.273 & -1.290 & 0.327 & 4.354 & -2.931 \\
SP & -0.693 & 6.343 & -13.806 & 0.590 & 3.545 & -3.003 \\
SW & -2.050 & 4.215 & -15.446 & -0.154 & 3.444 & -3.774 \\
UK & -2.219 & 3.753 & -13.001 & 1.074 & 7.895 & -2.873 \\
\hline \hline & Source: Own calculations based on EUROMOD.
\end{tabular}

the income shock and the base scenario (column 3) and the unemployment shock and the base scenario (column 4$)$, respectively $\left(\left(G_{\text {Shock }}^{Y^{D}}-G_{\text {Shock }}^{Y^{M}}\right)-\left(G_{B}^{Y^{D}}-G_{B}^{Y^{M}}\right)\right)$. The negative values indicate that both shocks lead to higher differences between the Gini coefficients based on equivalised disposable and market income. One conclusion of this finding is that post-shock inequalities in market income are even more reduced than in the base scenario, i.e. the automatic stabilizers increase the redistributive effects of the tax benefit systems in all countries in both scenarios. 
Table 5: Change in distribution and redistribution

\begin{tabular}{lrrr}
\hline \hline & $\Delta \% G_{U S-B}^{Y^{M}}$ & $\Delta\left(G^{Y^{D}}-G^{Y^{M}}\right)_{I S-B}$ & $\Delta\left(G^{Y^{D}}-G^{Y^{M}}\right)_{U S-B}$ \\
\hline AT & 1.564 & -0.003 & -0.006 \\
BE & 1.509 & -0.006 & -0.007 \\
DK & 2.673 & -0.005 & -0.013 \\
EE & 1.347 & -0.005 & -0.004 \\
FI & 1.737 & -0.005 & -0.007 \\
FR & 1.416 & -0.004 & -0.006 \\
GE & 1.827 & -0.004 & -0.008 \\
GR & 0.632 & -0.001 & -0.003 \\
HU & 0.836 & -0.002 & -0.003 \\
IR & 3.342 & -0.003 & -0.012 \\
IT & 0.798 & -0.003 & -0.002 \\
LU & 1.022 & -0.003 & -0.005 \\
NL & 1.766 & -0.003 & -0.005 \\
PL & 0.733 & -0.003 & -0.003 \\
PT & -0.353 & -0.002 & -0.001 \\
SI & 0.810 & -0.001 & -0.003 \\
SP & 1.178 & -0.002 & -0.004 \\
SW & 2.176 & -0.005 & -0.010 \\
UK & 2.204 & -0.006 & -0.008 \\
\hline \hline
\end{tabular}

Source: Own calculations based on EUROMOD.

\subsection{Stabilization of different income groups}

In this section, we refer to the income stabilization coefficient from Section 2.3, but focus on the stabilization of disposable income for different income groups. The income stabilization coefficient for quantile $q$ becomes:

$$
\tau_{q}^{I}=1-\frac{\sum_{q, i} \Delta Y_{q, i}^{D}}{\sum_{i} \Delta Y_{i}^{M}}=\frac{\sum_{q, i}\left(\Delta Y_{q, i}^{M}-\Delta Y_{q, i}^{D}\right)}{\sum_{i} \Delta Y_{i}^{M}}=\frac{\sum_{q, i} \Delta G_{q, i}}{\sum_{i} \Delta Y_{i}^{M}}
$$

Note that in the denominator, changes in market income for the total population are added up - as in equation (5). Hence, the sum of the five quantile coefficients yields the overall income stabilization coefficient. Table 6 shows that in case of the proportional income shock, the stabilization coefficients are an increasing function of the income quantiles. This result is due to higher changes between market and disposable income for high income groups. It is worth mentioning that even a proportional tax would yield increasing coefficients for higher quantiles, i.e. progressivity 
of the income tax is not required for this result.

In contrast to the increasing stabilization by income quantile for the income shock, stabilization results for the unemployment shock follow a somewhat different pattern as demonstrated in Table 7. Here, with the exception of some Eastern and Southern European countries, we find high stabilization also for the lowest income groups. As the unemployment shock is modeled through reweighting of our sample taking into account individual characteristics of the unemployed, a large part of the newly unemployed comes from lower income quantiles. The fact that tax and transfer systems in countries such as Estonia, Greece, Italy, Poland, Portugal, Slovenia or Spain provide only weak stabilization for low income groups can be explained by rather low unemployment benefits in these countries.

Table 6: Stabilization of income groups - Proportional Income Shock

\begin{tabular}{lllllll}
\hline \hline & TAU & Q1 & Q2 & Q3 & Q4 & Q5 \\
\hline AT & 0.439 & 0.023 & 0.045 & 0.072 & 0.107 & 0.192 \\
BE & 0.527 & 0.022 & 0.051 & 0.082 & 0.128 & 0.244 \\
DK & 0.558 & 0.017 & 0.046 & 0.088 & 0.135 & 0.273 \\
EE & 0.253 & 0.010 & 0.019 & 0.036 & 0.063 & 0.126 \\
FI & 0.396 & 0.010 & 0.031 & 0.063 & 0.099 & 0.192 \\
FR & 0.370 & 0.032 & 0.036 & 0.053 & 0.079 & 0.171 \\
GE & 0.481 & 0.019 & 0.045 & 0.072 & 0.116 & 0.228 \\
GR & 0.291 & 0.004 & 0.015 & 0.033 & 0.063 & 0.176 \\
HU & 0.476 & 0.029 & 0.041 & 0.056 & 0.097 & 0.254 \\
IR & 0.363 & 0.009 & 0.026 & 0.048 & 0.084 & 0.197 \\
IT & 0.346 & 0.010 & 0.035 & 0.051 & 0.077 & 0.173 \\
LU & 0.374 & 0.019 & 0.022 & 0.042 & 0.082 & 0.208 \\
NL & 0.397 & 0.020 & 0.040 & 0.062 & 0.093 & 0.182 \\
PL & 0.301 & 0.017 & 0.032 & 0.047 & 0.060 & 0.145 \\
PT & 0.303 & 0.012 & 0.013 & 0.029 & 0.055 & 0.194 \\
SI & 0.317 & 0.022 & 0.010 & 0.008 & 0.037 & 0.240 \\
SP & 0.277 & 0.006 & 0.020 & 0.036 & 0.062 & 0.153 \\
SW & 0.420 & 0.022 & 0.041 & 0.066 & 0.096 & 0.196 \\
UK & 0.352 & 0.010 & 0.034 & 0.047 & 0.079 & 0.182 \\
\hline \hline Source: Own calculations based on EUROMOD.
\end{tabular}

To further investigate which components of the tax and transfer systems drive the results for the five income quantiles, we decompose the income stabilization coefficient $\tau_{q}^{I}$ into its components income taxes, social insurance contributions (SIC) and benefits (Tables 9 and 10 in the Appendix). First, consider Table 9 for the 
Table 7: Stabilization of income groups - Unemployment Shock

\begin{tabular}{lllllll}
\hline \hline & TAU & Q1 & Q2 & Q3 & Q4 & Q5 \\
\hline AT & 0.585 & 0.111 & 0.094 & 0.069 & 0.130 & 0.181 \\
BE & 0.612 & 0.143 & 0.087 & 0.067 & 0.101 & 0.215 \\
DK & 0.823 & 0.095 & 0.189 & 0.166 & 0.196 & 0.177 \\
EE & 0.233 & 0.062 & 0.019 & 0.019 & 0.041 & 0.091 \\
FI & 0.519 & 0.118 & 0.057 & 0.074 & 0.093 & 0.176 \\
FR & 0.568 & 0.102 & 0.102 & 0.088 & 0.092 & 0.185 \\
GE & 0.624 & 0.144 & 0.078 & 0.090 & 0.118 & 0.193 \\
GR & 0.322 & 0.016 & 0.031 & 0.040 & 0.071 & 0.164 \\
HU & 0.467 & 0.091 & 0.045 & 0.048 & 0.071 & 0.212 \\
IR & 0.387 & 0.101 & 0.049 & 0.044 & 0.061 & 0.132 \\
IT & 0.311 & 0.011 & 0.021 & 0.047 & 0.081 & 0.151 \\
LU & 0.593 & 0.148 & 0.177 & 0.056 & 0.070 & 0.142 \\
NL & 0.452 & 0.123 & 0.048 & 0.054 & 0.088 & 0.140 \\
PL & 0.329 & 0.031 & 0.035 & 0.048 & 0.066 & 0.150 \\
PT & 0.386 & 0.014 & 0.005 & 0.040 & 0.075 & 0.252 \\
SI & 0.431 & 0.045 & 0.038 & 0.056 & 0.083 & 0.210 \\
SP & 0.376 & 0.038 & 0.049 & 0.065 & 0.076 & 0.148 \\
SW & 0.678 & 0.160 & 0.109 & 0.109 & 0.110 & 0.190 \\
UK & 0.415 & 0.142 & 0.034 & 0.030 & 0.060 & 0.150 \\
\hline \hline Source: Own calculations based on EUROMOD.
\end{tabular}

income shock scenario. Clearly, taxes and, to a smaller extent SIC, play a large stabilizing role for higher income quantiles whereas benefits are of minor importance for these income groups. This holds for all countries in our sample. Only in France, SIC are almost as important (fifth quantile) or even more important (fourth quantile) than taxes for stabilization of disposable income which can be explained with the progressive incidence of SIC. At the bottom of the distribution, stabilization of disposable income is rather low due to smaller changes in market income.

A different picture emerges again for the unemployment shock (Table 10). In this shock scenario, benefits play an important role, especially for low income quantiles. The decomposition convincingly shows which component of the tax and transfer systems causes the difference between Southern and Eastern European countries on the one hand and its neighbors on the other. The former group of countries has a rather low level of income stabilization mainly because unemployment benefits are substantially less generous in these countries. 


\subsection{Income stabilization and redistribution}

It is interesting to explore the relationship between the degree of income stabilization and redistribution which is achieved by the respective tax and transfer systems. Are systems with high automatic stabilizers also those which provide significant redistribution? To answer this question, we relate the degree of redistribution measured by the percentage difference in the Gini coefficients based on market and disposable income to the income stabilization coefficients for the income shock (Figure 2) and the unemployment shock (Figure 5 in the Appendix). The strong relationship between income stabilization and redistribution is reflected in very high (populationweighted) correlations of 0.67 (IS) and 0.86 (US).

Figure 2: Income Stabilization IS and Redistribution

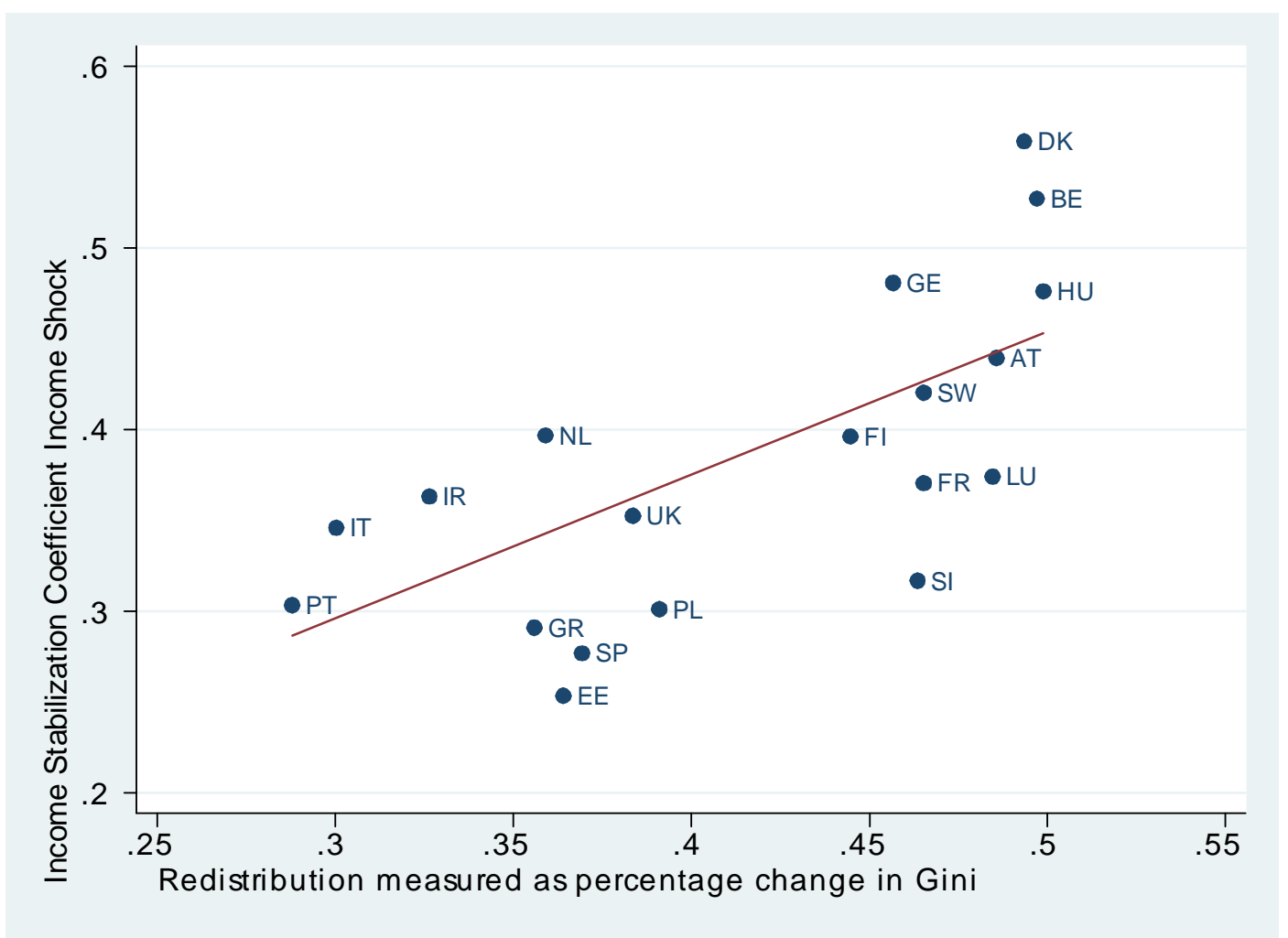

Source: Own calculations based on EUROMOD.

Next, we consider the relationship between the income stabilization coefficient and the ratio of direct to indirect taxes. We find a strong positive correlation of 0.67 (Figure 3). This is not surprising since the income stabilization coefficient 
positively depends on the level of direct taxes. In contrast, the mechanism how indirect taxes provide automatic stabilization is different as discussed in Dolls et al. (2009). There, we also find a positive relationship between the income stabilization and government size and openness, respectively, whereas no correlation is found between automatic stabilizers and active fiscal policy measures passed during the current economic crisis.

Figure 3: Income Stabilization IS and Ratio Direct to Indirect Taxes

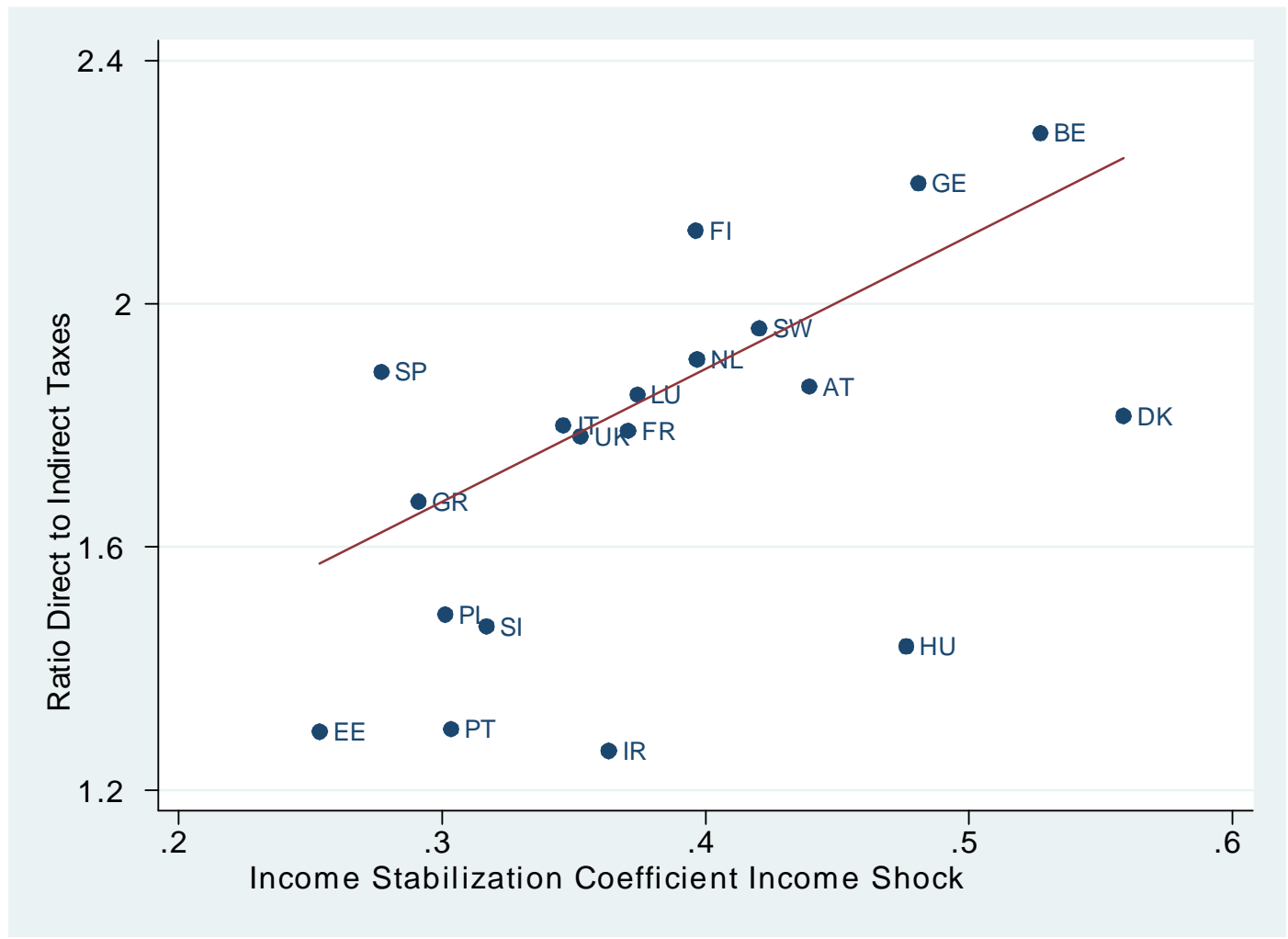

Source: Own calculations based on EUROMOD.

Table 8 shows the results of regressing the income stabilization coefficient (of the income shock) on our measure for redistribution, a measure for openness and the ratio of direct to indirect taxes. Redistribution is again measured as the percentage difference in the Gini coefficients based on market and disposable income and openness as the average ratio of exports and imports to GDP from 2000-2004.

Due to the very small sample size $(N=19)$, this inference should be interpreted with caution. Having this in mind, the significant positive relationships between automatic stabilizers and each of the variables is also confirmed by this "naïve" 
regression.

Table 8: Regressions on income stabilization coefficient IS

\begin{tabular}{l|llll} 
dep. var.: TAU Income Shock & $(1)$ & $(2)$ & $(3)$ & $(4)$ \\
\hline \hline Redistribution & $0.787^{* * *}$ & & & $0.441^{* *}$ \\
Openness & $(0.21)$ & & & $(0.19)$ \\
& & $0.109^{*}$ & & $0.082^{*}$ \\
Ratio Direct to Indirect Taxes & & $(0.06)$ & & $(0.04)$ \\
& & & $0.203^{* * *}$ & $0.154^{* * *}$ \\
Constant & & & $(0.06)$ & $(0.05)$ \\
& 0.060 & $0.302^{* * *}$ & 0.004 & -0.140 \\
\hline adjusted $\mathrm{R}^{2}$ & $(0.09)$ & $(0.04)$ & $(0.10)$ & $(0.09)$ \\
dof & 0.417 & 0.114 & 0.410 & 0.651 \\
$\mathrm{~F}$ & 17 & 17 & 17 & 15 \\
$\mathrm{~N}$ & 13.9 & 3.3 & 13.5 & 12.2 \\
\hline
\end{tabular}

Source: Own calculations based on EUROMOD.

Note: S.E. in parentheses. Significance level: ${ }^{*} \mathrm{p}<0.10,{ }^{* *} \mathrm{p}<0.05,{ }^{* * *} \mathrm{p}<0.01$

\subsection{Cluster Analysis}

In order to compare the clustering of countries with respect to the different measures of automatic stabilization and controlling for several variables, we conduct a hierarchical cluster analysis to group countries that have similar characteristics across a set of variables. When performing a cluster analysis, a number of technical decisions have to be made. First, all variables have been standardized from 0 to 1 using z-scores, to prevent that the results are driven by large absolute values of some variables. Our method of grouping the countries is the common Ward's linkage, which combines such clusters which minimally increase the squared sum of errors. Our results will be illustrated in a so-called dendrogram, which graphically presents the information concerning which observations are grouped together at various levels of (dis)similarity. At the bottom of the dendrogram, each observation is considered as its own cluster. Vertical lines extend up for each observation, and at various (dis)similarity values these lines are connected to the lines from other observations with a horizontal line. The observations continue to combine, until, at the top of the dendrogram, all observations are grouped together. The height of the vertical lines 
and the range of the (dis)similarity axis give visual clues about the strength of the clustering. In our case, the measure for the distance between cases is the common 'squared Euclidean'. Generally, long vertical lines indicate more distinct separation between groups, short lines more similarity, respectively. ${ }^{11}$

Figure 4: Cluster Analysis

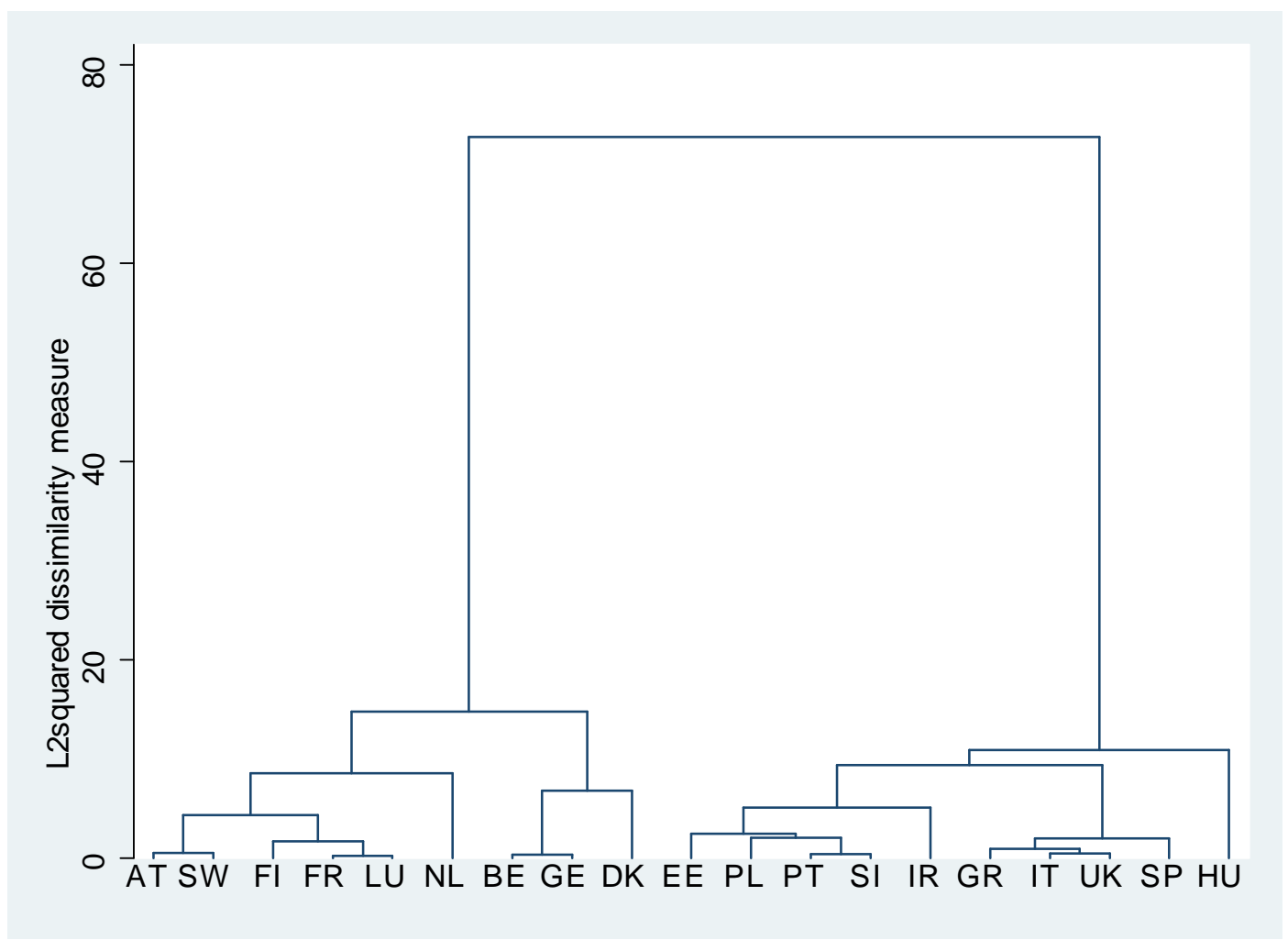

Source: Own calculations based on EUROMOD.

We perform a cluster analysis on the basis of the stabilization coefficients for the income and unemployment shock combined with inequality in market income and the ratio of direct to indirect taxes. The dendogram is illustrated in Figure 4. In accordance with the classical typology of welfare state regimes (Esping-Andersen (1990) and Ferrera (1996)), the dendogram groups Continental and Nordic countries to the left and Anglo-Saxon, Southern and Eastern European countries to the right. The former group is characterized by a rather high level of income stabiliza-

\footnotetext{
${ }^{11}$ Note that the general clustering results presented here are robust to different linkage or dissimilarity measure specifications. We report the results for the most common combination found in the literature.
} 
tion, modest inequality in market income and an important role of direct taxes and SIC, whereas countries from the latter group tend to rank at the other end of the spectrum.

\section{Conclusions}

This paper investigates the extent to which the tax and transfer system mitigates negative income and employment shocks at different income levels and in different countries. We have considered the distributional consequences of two types of shocks: a proportional shock on all incomes and an increase in unemployment which affects households asymmetrically. In both scenarios, post-shock inequalities in market income are even more reduced through the tax and transfer system than in the base scenario, i.e. the redistributive effects of the tax benefit systems increase in all countries.

Further, we investigate the degree of income stabilization for different income groups. In case of the proportional income shock, stabilization for higher income groups contributes relatively more to overall stabilization than stabilization for low income groups, but this is due to the larger absolute shock on gross income for the former group. A different pattern emerges in case of the unemployment shock. With the exception of some Eastern and Southern European countries, we find relatively high income stabilization coefficients also for low income groups. The stabilization for high income groups is mainly driven by the income tax. A notable exception to this is France where (progressive) social insurance contributions are most important for stabilization. For low income groups whose tax payments are negligible, benefits play a central role. As they are more generous in the Scandinavian and Western European countries, they contribute substantially more to stabilization of disposable income for lower income groups. We thus conclude that European tax benefit systems put unequal weights on the extent different income groups are protected against macro shocks.

With respect to the relationship between income stabilization and redistribution, we find that tax benefit systems with high automatic stabilizers are also those which are more effective in mitigating existing inequalities in market income. A simple regression of income stabilization on measures for openness, redistribution and the ratio of direct to indirect taxes confirms a significant positive relationship between 
the automatic stabilizers and each of the variables.

These results have to be interpreted in the light of various limitations of our analysis. Firstly, by modeling the unemployment shock through reweighting of the sample, we implicitly assume that the socio-demographic characteristics of the unemployed remain constant. Secondly, our analysis abstracts from automatic stabilization through other taxes, in particular corporate income taxes. ${ }^{12}$ Thirdly, we have abstracted from the role of labor supply or other behavioral adjustments for the impact of automatic stabilizers. We intend to pursue these issues in future research.

\footnotetext{
${ }^{12}$ For an analysis of automatic stabilizers in the corporate tax system see Devereux and Fuest (2009) and Buettner and Fuest (forthcoming).
} 


\section{A Appendix:}

\section{A.1 Additional results}

Figure 5: Income Stabilization US and Redistribution

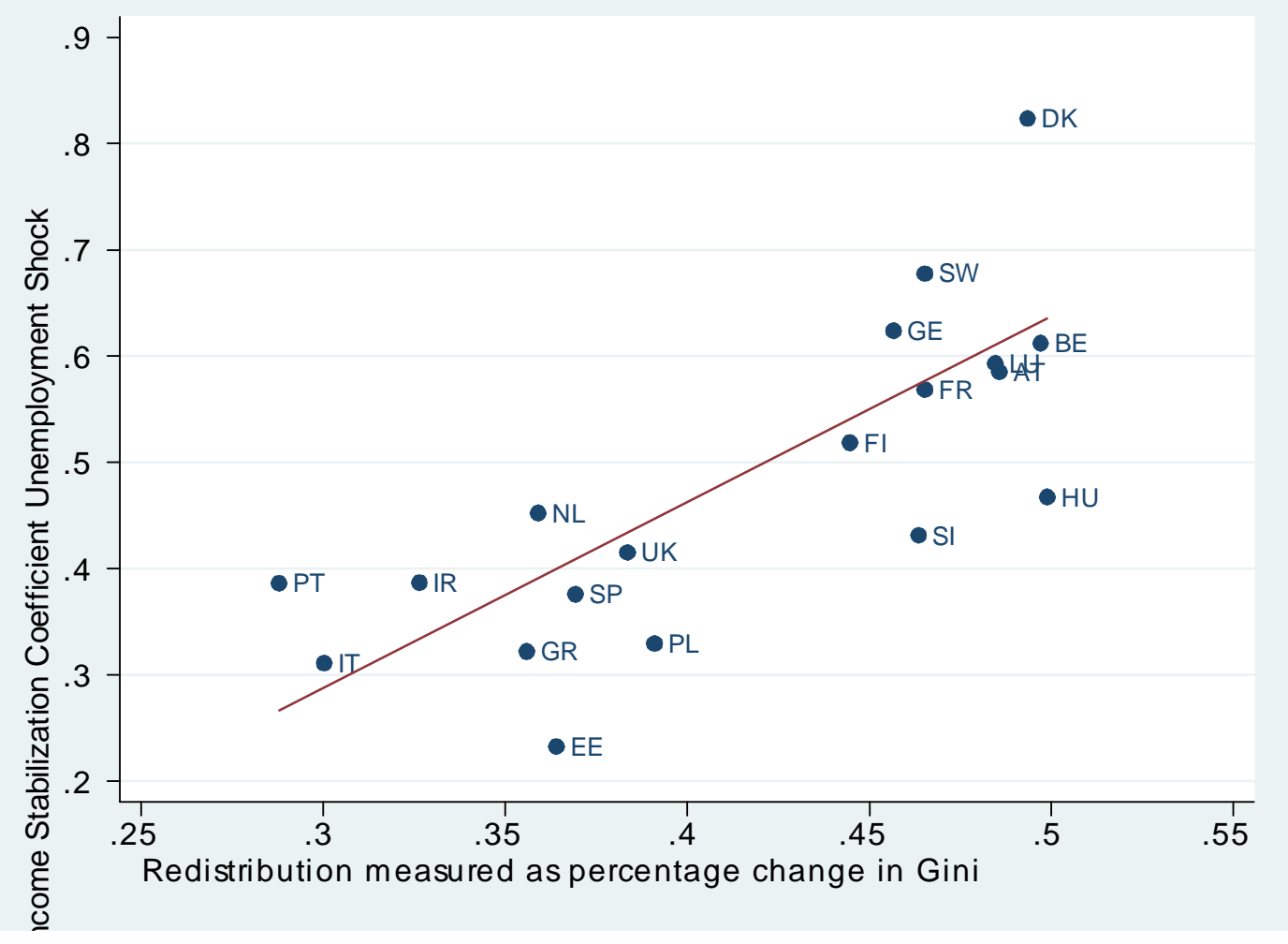

Source: Own calculations based on EUROMOD 


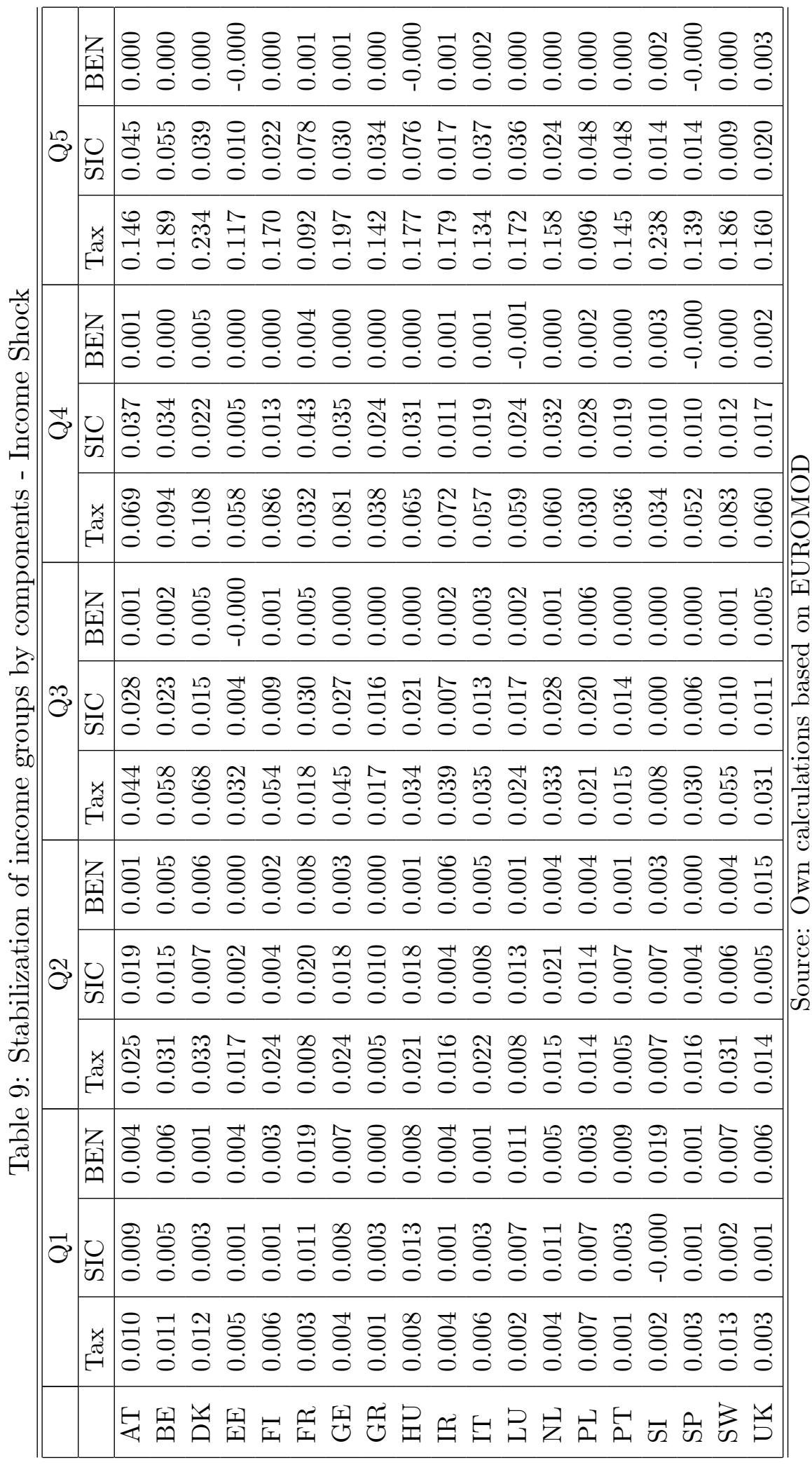




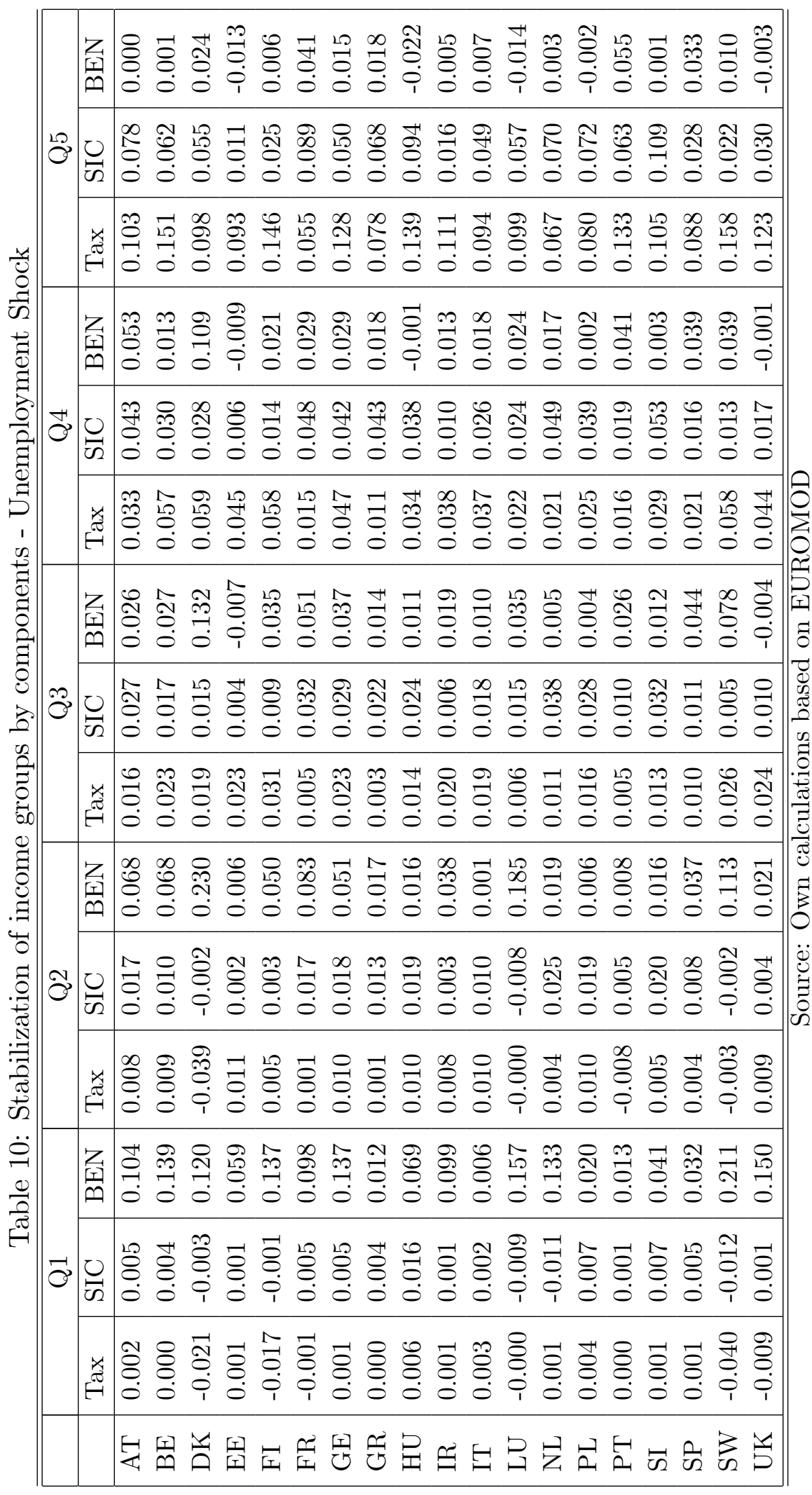




\section{A.2 Reweighting procedure for increasing unemployment}

In order to increase the unemployment rate while keeping the aggregate counts of other key individual and household characteristics constant, we follow the approach taken by Immvervoll et al. (2006). The increase of the unemployment rates is modeled through reweighting of our samples while controlling for several individual and household characteristics that determine the risk of becoming unemployed.

We follow Immvervoll et al. (2006) and define the unemployed as people aged 19-59 declaring themselves to be out of work and looking for a job. The withindatabase national 'unemployment rate' is calculated as the ratio of these unemployed to those in the labor force, defined as the unemployed plus people aged 19-59 who are (self)employed. The increased total number of unemployed people is calculated such that total household income decreases by $5 \%$ within each country.

In EUROMOD, the baseline household weights supplied with the national databases have been calculated to adjust for sample design and/or differential nonresponse (see Sutherland (2001) for details). Weights are then recalculated using the existing weights as a starting point, but (a) using the increased (decreased) number of unemployed (employed) people as the control totals for them, and (b) also controlling for individual demographic and household composition variables using the existing grossed-up totals for these categories as control totals. The specific variables used as controls are:

- employment status

- age (0-18, 19-24, 25-49, 50-59, 60+)

- gender

- marital status and household size

- education

- region

This method implies that the households without any unemployed people that are similar to households with unemployed people (according to the above variables) will have their weights reduced. In other words, these are the households who are 'made unemployed' in our exercise. 


\section{References}

Auerbach, A. and Feenberg, D. (2000). The significance of federal taxes as automatic stabilizers, Journal of Economic Perspectives 14: 37-56.

Bargain, O. (2006). Microsimulation in action: policy analysis in Europe using EUROMOD, vol. 25 of the series Research in Labor Economics, Elsevier.

Bargain, O., Immvervoll, H., Peichl, A. and Siegloch, S. (2010). Who are the losers of the labour-market downturn? A scenario analysis for Germany, Paper presented at IZA / OECD Workshop.

Bell, D. and Blanchflower, D. (2009). What Should Be Done about Rising Unemployment in the UK, IZA DP No. 4040.

Bourguignon, F. and Spadaro, A. (2006). Microsimulation as a tool for evaluating redistribution policies, Journal of Economic Inequality 4(1): 77-106.

Buettner, T. and Fuest, C. (forthcoming). The Role of the Corporate Income Tax as an Automatic Stabilizer, International Tax and Public Finance.

Callan, T., Nolan, B. and Walsh, J. (2010). The Economic Crisis, Public Sector Pay, and the Income Distribution, Paper presented at IZA / OECD Workshop.

Devereux, M. and Fuest, C. (2009). Is the Corporation Tax an Effective Automatic Stabilizer?, National Tax Journal LXII: 429-437.

Deville, J.-F. and Särndal, C.-E. (1992). Calibration estimators in survey sampling, Journal of the American Statistical Association 87: 376-382.

DiNardo, J., Fortin, N. and Lemieux, T. (1996). Labor Market Institutions and the Distribution of Wages, 1973-1992: A Semiparametric Approach, Econometrica 64: 1001-1044.

Dolls, M., Fuest, C. and Peichl, A. (2009). Automatic Stabilizers and Economic Crisis: US vs. Europe, IZA DP No.4310.

Domeij, D. and Floden, M. (forthcoming). Inequality trends in Sweden 1978-2004, Review of Economic Dynamics . 
Esping-Andersen, G. (1990). The Three Worlds of Welfare Capitalism, Blackwell Publishers Ltd., Oxford.

Ferrera, M. (1996). The 'Southern Model' of Welfare in Social Europe, Journal of European Social Policy 6 (1): 17-37.

Figari, F., Salvatori, A. and Sutherland, H. (2010). Economic Downturn and Stress testing European Welfare Systems, Paper presented at IZA / OECD Workshop.

Fuest, C., Niehues, J. and Peichl, A. (2010). The Redistributive Effects of Tax Benefit Systems in the Enlarged EU, Public Finance Review forthcoming.

Heathcote, J., Perri, F. and Violante, G. (forthcoming). Unequal We Stand: An Empirical Analysis of Economic Inequality in the US, 1967-2006, Review of Economic Dynamics 2010.

Herault, N. (2009). Sequential Linking of Computable General Equilibrium and Microsimulation Models, WP No. 2/09, Melbourne Institute of Applied Economic and Social Research, The University of Melbourne.

Immvervoll, H., Levy, H., Lietz, C., Mantovani, D. and Sutherland, H. (2006). The sensitivity of poverty rates to macro-level changes in the European Union, Cambridge Journal of Economics 30: 181-199.

Mabbett, D. and Schelkle, W. (2007). Bringing macroeconomics back into the political economy of reform: the Lisbon Agenda and the 'fiscal philosophy' of the EU, Journal of Common Market Studies 45: 81-104.

Reinhart, C. and Rogoff, K. (2009). The Aftermath of Financial Crisis, American Economic Review: Papers $\&$ Proceedings 99 (2): 466-472.

Sutherland, H. (2001). Final Report - EUROMOD: An Integrated European BenefitTax Model, EUROMOD Working Paper No. EM9/01.

Sutherland, H. (2007). Euromod: the tax-benefit microsimulation model for the European Union, in A. Gupta and A. Harding (eds), Modelling Our Future: Population Ageing, Health and Aged Care, Vol. 16 of International Symposia in Economic Theory and Econometrics, Elsevier, pp. 483-488. 